\title{
NEW COLUMN CONFIGURATIONS FOR PRESSURE SWING BATCH DISTILLATION II. RIGOROUS SIMULATION CALCULATIONS
}

\author{
Modla G. and P. Lang
}

\author{
Budapest University of Technology and Economics, \\ Department of Process Engineering, H-1521 Budapest, Muegyetem rkp. 3-5 \\ www.vegyelgep.bme.hu,lang@mail.bme.h
}

\begin{abstract}
The pressure swing distillation in different batch column configurations is investigated by rigorous simulation calculations. The calculations are made by a professional flow-sheet simulator for the separation of a minimum (ethanol-toluene) and a maximum boiling (water- ethylene-diamine) azeotropic mixture. Besides studying the well known configurations (rectifier, stripper) we also investigate two novel configurations such as double column batch rectifier and double column batch stripper. The alternate application of a batch rectifier and a batch stripper is also studied. The different column configurations are compared. Copyright (C) 2007 IFAC
\end{abstract}

Keywords: Pressure Swing Distillation, Batch Column Configurations, Rigorous Simulation

\section{INTRODUCTION}

Distillation is the separation method most frequently applied in the chemical industry, which is based on the difference of volatility of the components of a liquid mixture. For the separation of the two components $(\boldsymbol{A}$ and $\boldsymbol{B})$ forming an azeotrope a special distillation method must be applied such as the pressure swing distillation (PSD), extractive or heteroazeotropic distillation.

Batch distillation (BD) has always been an important part of seasonal, uncertain or low capacity and highpurity chemicals' production. It is a process of key importance in the pharmaceutical and several other industries and in the regeneration of waste solvent mixtures.

The main advantage of batch distillation over continuous is that a single apparatus can process many different liquid mixtures. Even multicomponent mixtures can be separated by batch distillation in a single column.

Many mixtures form an azeotrope, whose position can be shifted substantially by changing system pressure, that is, a pressure sensitive azeotrope.

Lewis (1928) was the first, who suggested to distill azeotropic mixtures by pressure swing distillation. This process has been suggested to separate azeotropic mixtures by e.g. Britton et al., 1943,
Black, 1980; Abu-Eishah and Luyben, 1985; Chang and Shis, 1989.

Knapp et al. (1992) developed a new process, in which pressure swing continuous distillation was combined with entrainer addition. The possibility of the application of an entrainer for the separation of binary azeotropic mixtures increases to a large extent the number of mixtures separable by this process.

Repke et al. (2006) investigated the separation of a minimum boiling, homoazeotropic mixture (acetonitrile-water) by pressure swing distillation in a batch rectifier (BR) and in a stripper (BS). The results were presented by pilot-plant measurements and rigorous simulations. The simulations fitted the experimental results with adequate accuracy. The aim of the authors was rather the experimental study of the batch pressure swing distillation than the exhausting theoretical study of the different configurations.

Modla and Lang (2007) studied the feasibility of pressure swing batch distillation (PSBD) of binary mixtures (forming minimum or maximum azeotrope) in different column configurations assuming maximal separation. They concluded that the MVC (having two column sections of different type) is not suitable for this process. They suggested two novel configurations having two rectifying (double column batch rectifier, DCBR) or two stripping sections 
(double column batch stripper, DCBS). They stated that these new configurations may provide a lot of advantages against the well-known simpler configurations (batch rectifier or stripper). They also studied the alternate application of a rectifier and a stripper (BR-BS), which can be applied for both minimum and maximum azeotropes.

In the industrial practice we can not produce maximal separation since

-the number of stages is limited,

-the reflux/reboil ratio is limited, and

-the liquid hold-up of the column section(s) is significant and must be taken into consideration.

For real operating conditions we have to make rigorous simulation calculations.

The aim of the paper is

-to verify the conclusions of the feasibility studies,

-to investigate the performance of the above feasible configurations,

-to compare the different configurations

with rigorous simulation calculations.

The calculation results are presented for the mixtures ethanol $(\boldsymbol{A})$ - toluene $(\boldsymbol{B})$ (minimum boiling point azeotrope,) and water $(\boldsymbol{A})$ - ethylene-diamine $(\boldsymbol{B})$ (maximum boiling point azeotrope).

\section{VLE CONDITIONS}

The equilibrium diagrams and azeotropic data at the different pressures of the mixtures studied are shown in Fig. 1 and Table 1, respectively.

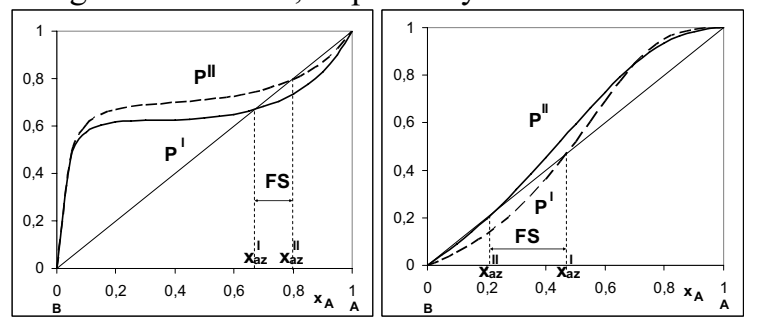

Fig. 1. $y$ - $x$ diagrams of the mixtures

a. ethanol - toluene b. water- EDA

$\left(P^{\mathrm{I}}=0.1, P^{\mathrm{II}}=1.1\right.$ bar $) \quad\left(P^{\mathrm{I}}=0.1, P^{\mathrm{II}}=8.0\right.$ bar $)$

Table 1. Data of azeotropes

\begin{tabular}{|l|c|c|c|c|c|}
\hline \multicolumn{1}{|c|}{ Mixture } & $\begin{array}{c}\boldsymbol{P} \\
\text { bar }\end{array}$ & $\begin{array}{c}\boldsymbol{x}_{\mathrm{az}} \\
{[\mathbf{\%}]}\end{array}$ & $\begin{array}{c}\boldsymbol{T}_{\mathrm{az}} \\
{\left[{ }^{\circ} \mathbf{C}\right]}\end{array}$ & $\begin{array}{c}\boldsymbol{T}_{\mathbf{B P}, \mathbf{A}} \\
{\left[{ }^{\circ} \mathbf{C}\right]}\end{array}$ & $\begin{array}{c}\boldsymbol{T}_{\mathbf{B P}, \mathbf{B}} \\
{\left[{ }^{\circ} \mathbf{C}\right]}\end{array}$ \\
\hline Ethanol $(\boldsymbol{A})-$ & 0.1 & 67 & 26.4 & 29.1 & 45.3 \\
Toluene $(\boldsymbol{B})$ & 1.1 & 79 & 78.8 & 80.4 & 113.6 \\
\hline Water (A)- & 0.1 & 47 & 62.2 & 45.8 & 50.8 \\
EDA $(\boldsymbol{B})$ & 8.0 & 21 & 199.5 & 170.5 & 198.6 \\
\hline
\end{tabular}

By varying the pressure the azeotropic compositions are shifted. For both mixtures the difference of the two azeotropic compositions is more than $5 \%$, and the difference of the two pressures applied is less than 10 bars, so the pressure swing process for the separation can be economical (Perry et al., 1998).

\section{RIGOROUS SIMULATION CALCULATIONS}

After the feasibility studies (Modla and Lang, 2007) we performed rigorous simulation calculations for real operating conditions.

\subsection{Simulation method}

The following simplifying assumptions were applied

- theoretical stages,

- negligible vapour hold-up,

- constant volumetric liquid plate hold-up.

The model equations to be solved are well known:

a. Non-linear differential equations (material balances, heat balances)

b. Algebraic equations (vapour-liquid equilibrium (VLE) relationships, summation equations, hold-up equivalence, physical property models).

For the calculations we used the CCDCOLUMN flow-sheet simulator of Chemstations (2006).

The following modules were applied:

-DYNCOLUMN (column sections, simultaneous correction method),

-DYNAMIC VESSEL (vessel and product tanks),

-HEAT EXCHANGER, PUMP, VALVE,

-MIXER, DIVIDER.

\subsection{Simulation results}

The following configurations are studied. For the separation of

a. maximum azeotropes: BR, BR-BS, DCBR

b. minimum azeotropes: BS, BR-BS, DCBS

The number of theoretical stages for each column sections is 20. (The total condenser and reboiler do not provide a theoretical stage.) For the sake of simplicity we specified the same reflux/reboil ratio for the different steps (BR, BS, BR-BS) and columns (DCBR, DCBS). The liquid hold-up for the configurations with one column section is 50 $\mathrm{cm}^{3} /$ plate whilst for the DCBR, DCBS (operated under lower vapour load) $25 \mathrm{~cm}^{3}$, respectively. The quantity of the charge is $11 \mathrm{dm}^{3}$. At the start the column is filled up with boiling point liquid feed. The duration of the start-up period (purification without product withdrawal) is $60 \mathrm{~min}$. The whole process is finished

-for the BR, BS and BR-BS: when the duration of any production step becomes shorter than $15 \mathrm{~min}$,

-for the DCBR and DCRS: when the amount of liquid in the vessel decreases to $2 \%$ of the charge.

\subsubsection{Separation of a maximum azeotrope}

The charge contains 40 mole $\%$ water.

\section{a. Batch rectifier}

The flow rate of vapour leaving the reboiler (boil-up rate): $V_{\mathrm{reb}}=340 \mathrm{~mol} / \mathrm{h}$. The speed of the pressure change: $\mathrm{d} P / \mathrm{d} t=1 \mathrm{bar} / \mathrm{min}$. Criteria for the product (distillate) withdrawals:

-start: under $R=\infty$ for 3 minutes the instantaneous product purity is at least $99 \%\left(x_{\mathrm{W}} \geq 0.99\right.$ or $\left.x_{\mathrm{W}} \leq 0.01\right)$ -end: it falls below $0.95\left(x_{\mathrm{W}}<0.95\right.$ or $\left.x_{\mathrm{W}}>0.05\right)$

The evolution of the pressure, product and vessel residue compositions $\left(x_{\mathrm{VR}}\right)$ are shown in Figs. 2.

With the progress of the process

-the production periods become shorter and shorter, -the vessel composition varies more and more quickly and in a wider and wider region.

The results are summarised in Table 2 .

High product purities were reached: $x_{\mathrm{W}, \mathrm{A}, \mathrm{av}}=99,0 \%$ $x_{\mathrm{W}, \mathrm{B}, \mathrm{av}}=99.3 \%$. 

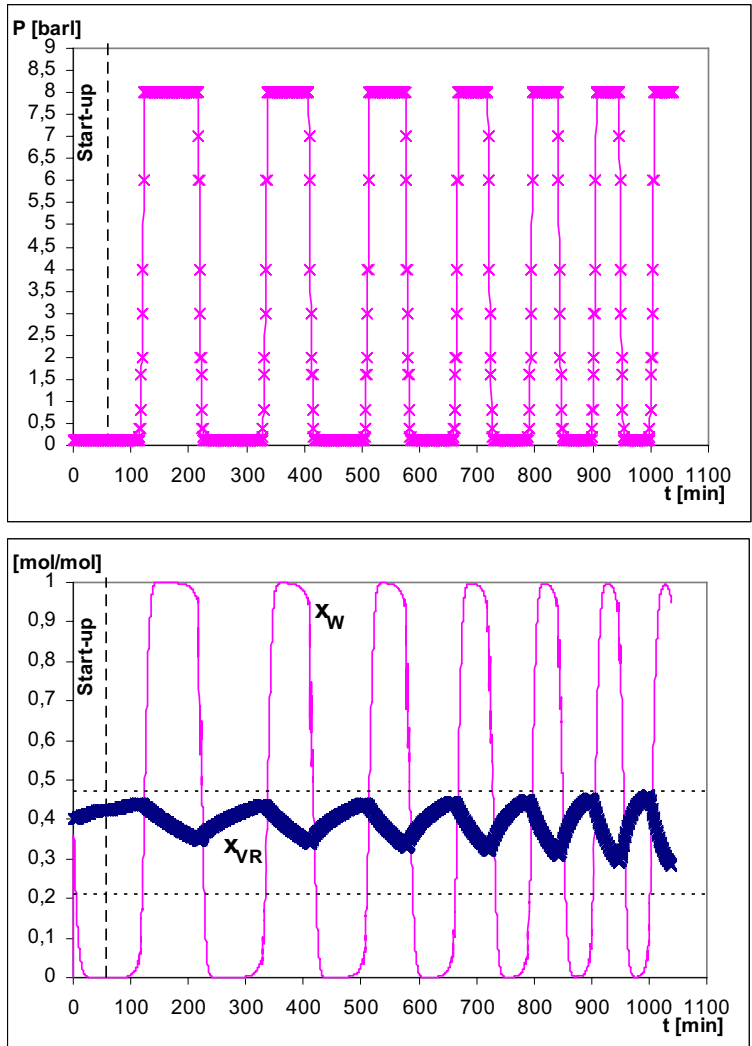

Figs. 2. Evolution of the pressure (a), product and vessel residue compositions (b) for the BR

The recoveries $\left(\eta_{\mathrm{i}}\right)$ of both components are reasonable: $\eta_{\mathrm{A}}=88.7 \%$ and $\eta_{\mathrm{B}}=86.2 \%$.

The duration of the periods without product withdrawal (purification of the product, pressure change) is considerable ( $44.2 \%$ of the total process time).

\section{b. Combination of a batch rectifier and a stripper}

We begin the cycle with a low pressure stripping step. Before this step the charge is filled in the top vessel. The flow rate of liquid leaving the top vessel: $L_{0}=340 \mathrm{~mol} / \mathrm{h}$. In the 2 nd step of the cycle high pressure rectification is performed. (Before this step the feed is already in the bottom vessel, which was the product tank in the previous step.) The boil-up rate: $V_{\mathrm{reb}}=340 \mathrm{~mol} / \mathrm{h}$. After the end of the rectifying steps before the beginning a new cycle (with stripping) the bottom vessel residue must be filled in the top vessel.

The average speed of the (non-linear) pressure change: $\mathrm{d} P / \mathrm{d} t=1 \mathrm{bar} / \mathrm{min}$. Criteria for ending the product withdrawals

- in the stripping steps: the vessel residue attains a purity of $98 \%\left(x_{\mathrm{W}, \text { av }}=0.02\right)$

- in the rectifying steps:

-start: under $R=\infty$ for 3 minutes the instantaneous product purity is at least $99 \%\left(x_{\mathrm{W}} \geq 0.99\right)$

-end: it falls below $0.95\left(x_{\mathrm{W}}<0.95\right)$

The evolution of the pressure, (instantaneous) top vapour and bottom liquid compositions are shown in Figs. 3.

In the start-up period under $R_{\mathrm{S}}=\infty$ of the first stripping the bottom liquid takes the azeotropic composition quickly and it remains at this composition until the end of the step. In the
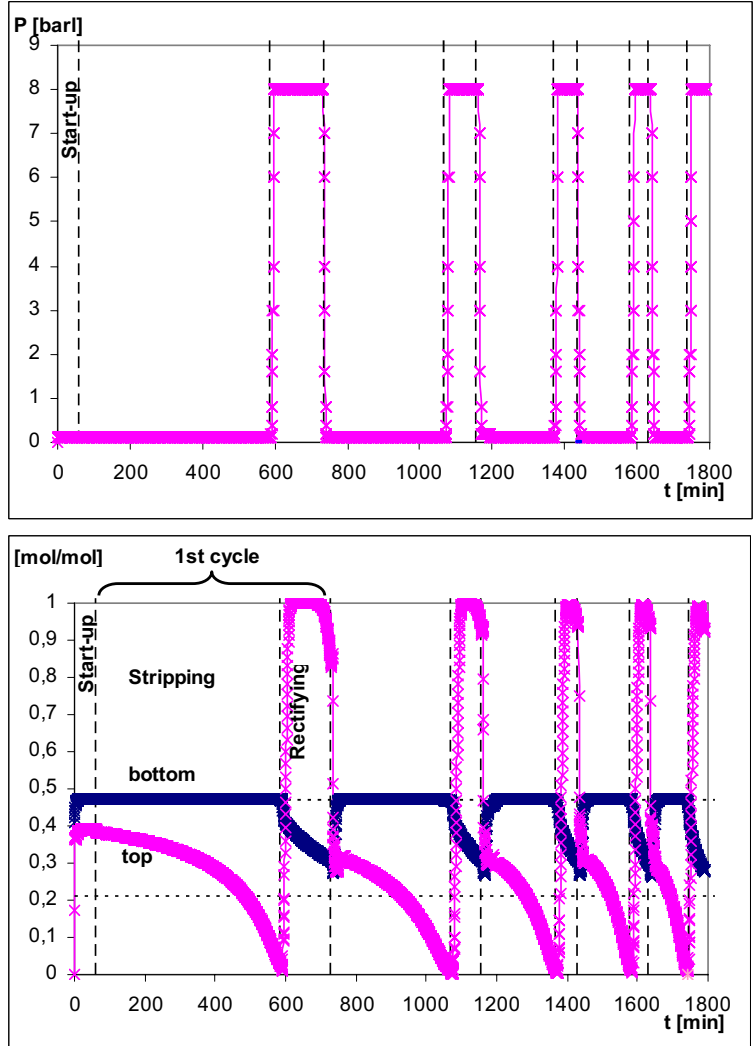

Figs. 3. Evolution of the pressure (a), top vapour and bottom liquid compositions (b) for the BR-BS

production period (under $R_{\mathrm{S}}<\infty$ ) of this step the concentration of water in the top vapour (and also in the top vessel liquid) progressively decreases and finally the top vessel liquid reaches the prescribed EDA purity. At the beginning of the rectifying step (in the start-up period under $R=\infty$ ) the top vapour gets pure enough within a few minutes. In the rectifying step pure water is produced as distillate and the vessel composition is moving towards the high pressure azeotropic composition.

The prescribed purity products were obtained with reasonable $(82.7$ and $82.0 \%)$ recoveries. However these recoveries were lower than those obtained (for higher product purities) for the batch rectifier. The duration of the periods without product withdrawal (purification of the product, pressure change) is considerable ( $19.0 \%$ of the total process time).

All parameters characterising the performance of the process are the worst for this configuration (Table 2).

\section{c. Double column batch rectifier}

The flow rates of vapour leaving the reboiler (boil-up rate): $V_{\text {reb }}{ }^{\mathrm{II}}=0.4 \times 340=136 \mathrm{~mol} / \mathrm{h}$ and $V_{\mathrm{reb}}{ }^{\mathrm{I}}=204 \mathrm{~mol} / \mathrm{h}$. The pressure of the columns does not change in time: $P^{\mathrm{I}}=0.1$ bar and $P^{\mathrm{II}}=8$ bar.

The evolution of the product and vessel residue compositions is shown in Fig. 4.

Both products get pure quickly (within less than 20 minutes) and both purities remain high for a very long period. The vessel composition is kept within a very narrow interval (between 39.0 and $40.1 \%$ ).

By this new configuration the highest product purities (99.99 and $99.97 \%$ ) and the best recoveries (90.2 and 92.6) were reached. There is only one period without product withdrawal (purification of the distillate at the beginning) whose duration is less 


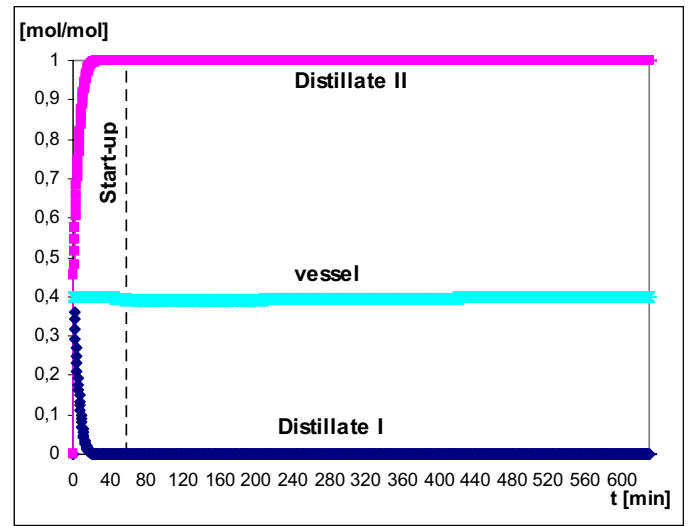

Fig. 4. Evolution of the product and vessel residue compositions (DCBR)

than $10 \%$ of the total process time (which could be still decreased). All parameters characterising the performance of the process are the best for this configuration (Table 2). By thermal coupling of the condenser of the high pressure column $\left(Q_{\text {cond }}{ }^{\mathrm{II}}=\right.$ $4.75 \mathrm{MJ} / \mathrm{h}, T_{\text {cond }}{ }^{\mathrm{II}}=\mathrm{cca} .170{ }^{\circ} \mathrm{C}$ ) with the reboiler of the low pressure column $\left(Q_{\text {reb }}{ }^{\mathrm{I}}=7.5 \mathrm{MJ} / \mathrm{h}, T_{\text {reb }}{ }^{\mathrm{II}}=\right.$ cca. $77{ }^{\circ} \mathrm{C}$ ) further energy $(34 \%$ of the total heat duty of the two column system) can be saved.

\subsubsection{Separation of a minimum azeotrope}

The charge contains 71 mole $\%$ of ethanol.

\section{a. Batch stripper}

The flow rate of liquid leaving the top vessel: $L_{0}=$ $340 \mathrm{~mol} / \mathrm{h}$. The speed of the pressure change: $\mathrm{d} P / \mathrm{d} t=$ $0.2 \mathrm{bar} / \mathrm{min}$. Criteria for the product withdrawal: -start: under $R_{\mathrm{S}}=\infty$ for 3 minutes the instantaneous product purity is at least $99 \%\left(x_{\mathrm{W}} \leq 0.01\right.$ or $\left.x_{\mathrm{W}} \geq 0.99\right)$ -end: it falls below $0.95\left(x_{\mathrm{W}}>0.05\right.$ or $\left.x_{\mathrm{W}}<0.95\right)$
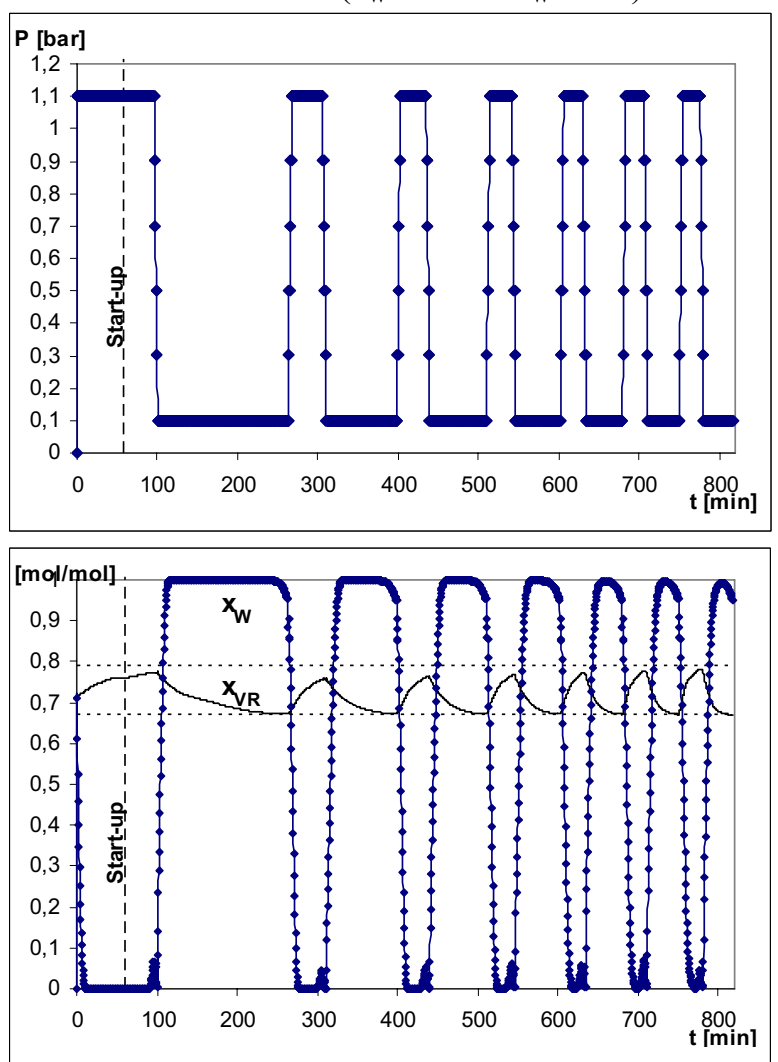

Figs. 5. Evolution of the pressure (a), product and vessel residue compositions (b) for the BS
The evolution of the pressure, product and vessel residue compositions are shown in Figs. 5.

With the progress of the process

-the production periods become shorter and shorter, -the vessel composition varies more and more quickly and in a wider and wider region.

High product purities $(99.4,99.4 \%)$ with reasonable recoveries $(80.4,78.0 \%)$ were reached. The duration of the periods without product withdrawal (purification of the product, pressure change) is very long $(52.9 \%$ of the total process time $)$.

\section{b. Combination of a batch rectifier and a stripper}

We begin the cycle with a low pressure rectifying step. Before this step the charge is filled in the bottom vessel. The boil-up rate: $V_{\text {reb }}=340 \mathrm{~mol} / \mathrm{h}$. In the 2 nd step of the cycle high pressure stripping is performed. (In the stripping step the feed is the distillate of the rectifying step.) The flow rate of liquid entering the column: $L_{0}=340 \mathrm{~mol} / \mathrm{h}$. After the end of the stripping steps before the beginning of a new cycle (with rectification) the top vessel residue must be filled into the bottom vessel.

The average speed of the pressure change: $\mathrm{d} P / \mathrm{d} t=0.2$ $\mathrm{bar} / \mathrm{min}$. Criteria for ending the product withdrawals - in the rectifying steps: the vessel residue attains a purity of $98 \%\left(x_{\mathrm{VR}} \geq 0.98\right)$

- in the stripping steps:

-start: under $R_{\mathrm{S}}=\infty$ for 3 minutes the instantaneous product purity is at least $99 \%$ for $\boldsymbol{B}\left(x_{\mathrm{W}} \leq 0.01\right)$

-end: it falls below $5 \%\left(x_{\mathrm{W}}>0.05\right)$.

The evolution of the pressure, (instantaneous) top vapour and bottom liquid compositions is shown in Figs. 6.
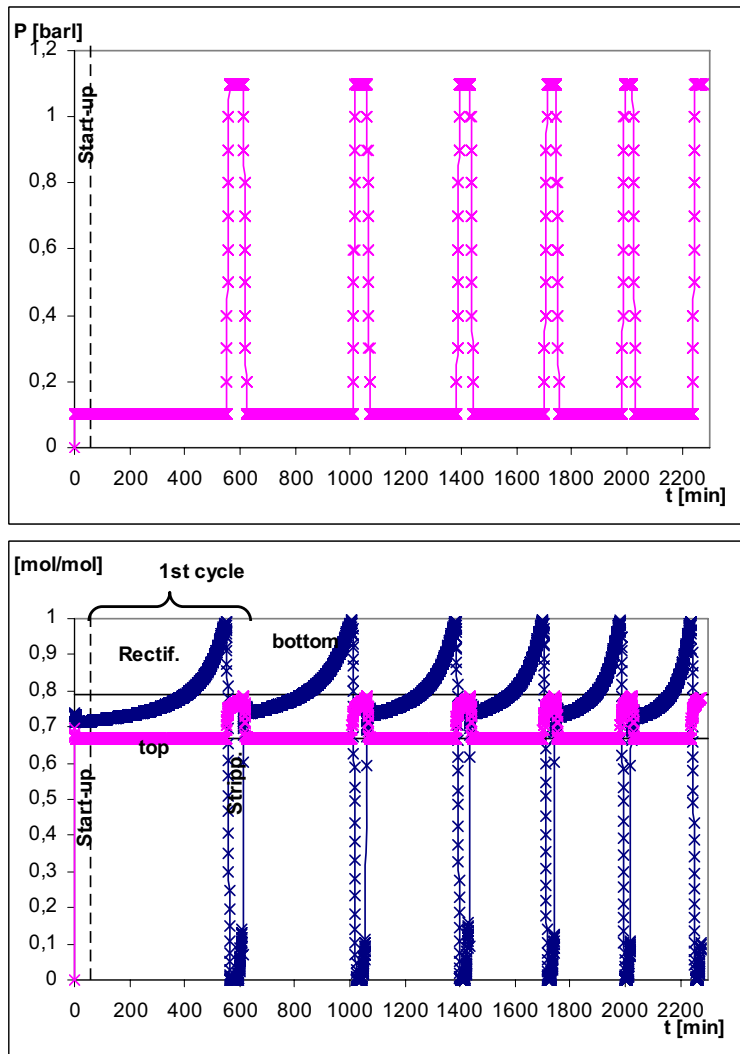

Figs. 6 Evolution of the pressure (a), top vapour and bottom liquid compositions (b) for BR-BS 
In the start-up period under $\mathrm{R}=\infty$ of the first rectification the top vapour (distillate) takes the azeotropic composition quickly and it remains at this composition until the end of the step. In the production period (under $R<\infty$ ) of this step the concentration of ethanol in the bottom liquid (and also in the bottom vessel liquid) progressively increases and finally the bottom vessel liquid reaches the prescribed ethanol purity.

At the beginning of the stripping step (in the start-up period under $R_{\mathrm{S}}=\infty$ ) the ethanol content of the bottom liquid falls quickly and pure toluene is continuously produced as bottom product. The top vapour (and the top vessel) composition is moving towards the high pressure azeotropic composition.

The prescribed purity products were obtained with reasonable (63.1 and 94.5\%) recoveries. However these recoveries were lower than those obtained (for higher product purities) for the batch stripper. The duration of the periods without product withdrawal (purification of the product, pressure change) is considerable (14.7\% of the total process time).

All parameters characterising the performance of the process are the worst for this configuration (Table 3 ).

\section{c. Double column batch stripper}

The flow rates of liquid entering the columns from the common top vessel: $L_{0}{ }^{\mathrm{I}}=0.72 \times 340=244.8 \mathrm{~mol} / \mathrm{h}$ and $L_{0}{ }^{\mathrm{II}}=95.2 \mathrm{~mol} / \mathrm{h}$. The pressures of the columns do not change in time: $P^{\mathrm{I}}=0.1$ bar and $P^{\mathrm{II}}=1.1$ bar. The evolution of product and vessel residue compositions is shown in Fig. 7.

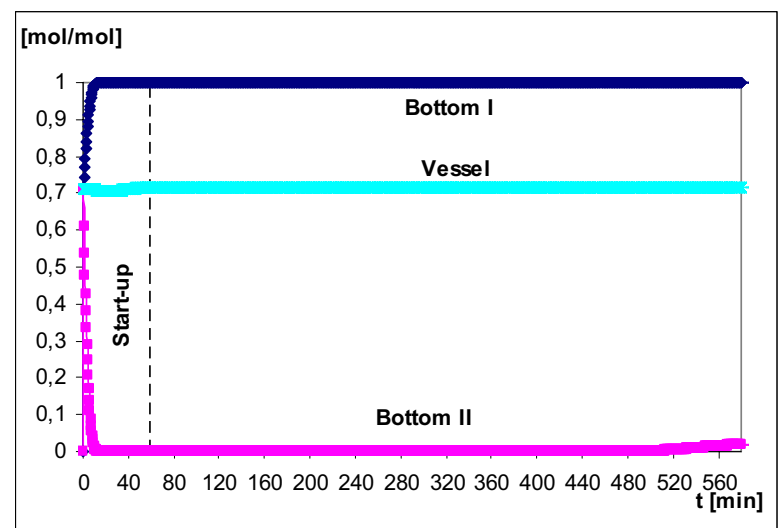

Fig. 7. Evolution of the product and vessel residue compositions (DCBS)

Both products get pure very quickly (within less than 10 minutes) and both product purities remain very high for a very long period. The vessel composition is kept within a very narrow interval (between 70.6 and $71.6 \%$ ).

By this new configuration the highest product purities (99.99 and $99.86 \%$ ) and the best recoveries (92.3 and 97.8) were reached. There is only one period without product withdrawal (purification of the product at the beginning) whose duration was less than $10 \%$ of the total process time (and which could be still decreased). All parameters characterising the performance of the process were the best for this configuration (Table 3 ).

By thermal coupling of the condenser of the high pressure column $\left(Q_{\text {cond }}{ }^{\mathrm{II}}=-10.38 \mathrm{MJ} / \mathrm{h}, T_{\text {cond }}{ }^{\mathrm{II}}=\mathrm{cca}\right.$. $26.4^{\circ} \mathrm{C}$ ) with the reboiler of the low pressure column $\left(Q_{\text {reb }}{ }^{\mathrm{I}}=+3.44 \mathrm{MJ} / \mathrm{h}, T_{\text {reb }}{ }^{\mathrm{II}}=\right.$ cca. $\left.114{ }^{\circ} \mathrm{C}\right)$ further energy $(25 \%$ of the total heat duty of the two column system) can be saved.

Table 2. Results for the different configurations (maximum azeotrope)

\begin{tabular}{|l|l|l|l|l|}
\hline & & BR & BR-BS & DCBR \\
\hline $\begin{array}{l}\text { Water } \\
\text { recovery }\end{array}$ & $\%$ & 88.7 & 82.7 & 90.2 \\
\hline $\begin{array}{l}\text { EDA } \\
\text { recovery }\end{array}$ & $\%$ & 86.2 & 82.0 & 92.6 \\
\hline $\begin{array}{l}\text { Water } \\
\text { purity }\end{array}$ & $\mathrm{mol} \mathrm{\%}$ & 98.99 & 98.02 & 99.99 \\
\hline $\begin{array}{l}\text { EDA } \\
\text { purity }\end{array}$ & $\mathrm{mol} \mathrm{\%}$ & 99.35 & 98.03 & 99.97 \\
\hline $\begin{array}{l}\text { Water } \\
\text { energy } \\
\left(S Q / S W_{\mathrm{A}}\right)\end{array}$ & $\mathrm{MJ} / \mathrm{mol}$ & 5.98 & 10.8 & 3.77 \\
\hline $\begin{array}{l}\text { EDA energy } \\
\left(S Q / S W_{\mathrm{B}}\right)\end{array}$ & $\mathrm{MJ} / \mathrm{mol}$ & 4.10 & 7.28 & 2.45 \\
\hline $\begin{array}{l}\text { Total } \\
\text { energy }\end{array}$ & $\mathrm{MJ}$ & 495.6 & 836.6 & 316.6 \\
\hline Total time & $\mathrm{min}$ & 1039 & 1790 & 687 \\
\hline $\begin{array}{l}\text { Production } \\
\text { time }\end{array}$ & $\mathrm{min}$ & 598 & 1451 & 627 \\
\hline
\end{tabular}

Table 3. Results for the different configurations (minimum azeotrope)

\begin{tabular}{|l|l|l|l|l|}
\hline & & BS & BR-BS & DCBS \\
\hline $\begin{array}{l}\text { EtOH } \\
\text { recovery }\end{array}$ & $\%$ & 80.4 & 63.1 & 92.3 \\
\hline $\begin{array}{l}\text { Toluene } \\
\text { recovery }\end{array}$ & $\%$ & 78.0 & 94.5 & 97.8 \\
\hline $\begin{array}{l}\text { EtOH } \\
\text { purity }\end{array}$ & $\mathrm{mol} \%$ & 99.4 & 98.3 & 99.99 \\
\hline $\begin{array}{l}\text { Toluene } \\
\text { purity }\end{array}$ & $\mathrm{mol} \%$ & 99.4 & 98.3 & 99.86 \\
\hline $\begin{array}{l}\text { EtOH } \\
\text { energy } \\
\left(S Q / S W_{\mathrm{A}}\right)\end{array}$ & $\mathrm{MJ} / \mathrm{mol}$ & 4.22 & 15.72 & 3.08 \\
\hline $\begin{array}{l}\text { Toluene en. } \\
\left(S Q / S W_{\mathrm{B}}\right)\end{array}$ & $\mathrm{MJ} / \mathrm{mol}$ & 10.6 & 25.71 & 7.11 \\
\hline $\begin{array}{l}\text { Total } \\
\text { Energy }\end{array}$ & $\mathrm{MJ}$ & 369.4 & 1080 & 311.5 \\
\hline Total time & $\mathrm{min}$ & 877 & 2274 & 680 \\
\hline $\begin{array}{l}\text { Production } \\
\text { time }\end{array}$ & $\mathrm{min}$ & 464 & 1939 & 620 \\
\hline
\end{tabular}

\section{CONCLUSION}

The pressure swing distillation was studied in different batch column configurations by using the CCDCOLUMN professional flowsheet simulator. On the basis of the results of feasibility studies (Modla and Lang, 2007) we investigated and compared the following configurations for

- minimum azeotropes: batch stripper (BS), double column batch stripper (DCBS),

- maximum azeotropes: batch rectifier (BR), double column batch rectifier (DCBR) and

- for both types of azeotrope: the alternate application of a rectifier and a stripper. 
As it was expected by the results of feasibility studies the best results were obtained with the two new configurations (DCBS and DCBR), which do not require pressure change during the process. The rectifier-stripper combination proved to be less efficient than the simplest configurations (BS and BR). We also proved that both column sections of the new DCBS and DCBR configurations can be operated practically under steady state conditions.

\section{REFERENCES}

- Abu-Eishah S. I., Luyben W. L. "Design and Control of Two-Column Azeotropic Column Azeotropic Distillation system", Ind. Eng. Chem. Process. Des. Dev. 24, 132-140, (1985).

- Black C. "Distillation Modelling of Ethanol Recovery and Dehydration Processes for Ethanol and Gasahol”, Chem. Eng. Prog., 76, 78-85, (1980).

- Britton E. C., Nuttiing H. S., Horley L. H. "Separation of Ketones and Monohydric Alcohols from Mixtures Thereof.", U.S. Patent, 2,324,255, July 13, (1943)

- Chang T., Shih T. T. "Development of an Azeotropic Distillation Scheme for Purification of Tetrahydrofuran", Fluid Phase Equilib., 52, 161, 161-168. (1989).

- Chemstations, "CHEMCAD User Guide" (2005).

- Knapp J.P. and M.F. Doherty "A new pressure swing-distillation process for separating homogeneous Azeotropic Mixtures", Ind. Eng. Chem. Res., 31, 346-357, (1992).

- Lewis W. K., "Dehydrating Alcohol and the Like", U.S. Patent, 1,676,700, July 10, (1928).

- Luyben W. L., "Comparison of Pressure Swing and Extractive Distillation Methods for Metanol Recovery Systems...”, Ind. Eng. Chem. Res., 44(15), 5715-25 (2005).

- Modla G. and P. Lang "Pressure swing distillation in different batch column configurations I. Feasibility Studies", DYCOPS2007.

- Perry R. H., D.W. Green, J.O. Maloney, ”Perry’s Chemical Engineer's Handbook" Seventh edition, McGraw Hill, New York, (1998)

- Repke .J. U., Klein A., Bogle D., Wozny G., "Pressure Swing Batch Distillation for Homogenous Azeotropic Separation", Proceedings of Distillation and Absorption 2006, London, 709-718.

\section{NOTATION}

F amount of feed [mol]

$L_{0} \quad$ Reflux molar flow rate $[\mathrm{mol} / \mathrm{s}]$

$N \quad$ number of theoretical stages

$P \quad$ pressure [bar]

$Q \quad$ heat duty [W]

$R \quad$ reflux ratio $[\mathrm{mol} / \mathrm{mol}]$

$R_{\mathrm{S}} \quad$ boil up ratio $[\mathrm{mol} / \mathrm{mol}]$

$S D \quad$ amount of the top product [mol]

$S Q \quad$ amount of heat [J]

$S W \quad$ amount of the product [mol]

$t \quad$ time [s]

$V \quad$ boil-up molar flow rate $[\mathrm{mol} / \mathrm{s}]$

$W \quad$ molar flow rate of the product continuously withdrawn $[\mathrm{mol} / \mathrm{s}]$ $x \quad$ liquid mol fraction $[\mathrm{mol} / \mathrm{mol}]$

$y \quad$ vapour mol fraction $[\mathrm{mol} / \mathrm{mol}]$

$z$ feed/charge composition $[\mathrm{mol} / \mathrm{mol}]$

\section{Greek letters}

$\eta \quad$ recovery

\section{Subscripts}

A pure component $\boldsymbol{A}$

av average

az azeotrope

B pure component $\boldsymbol{B}$

BL bottom liquid

TV top vapour

$\mathrm{V}$ vessel

VR residue in the vessel

W product

\section{Superscripts}

1,2 column index

HP high pressure

I, II pressure index

LP low pressure

vol volumetric

\section{ACKNOWLEDGEMENT}

This work was financially supported by the Hungarian Scientific Research Fund (No: T-049184) and National Office for Research and Technology (KPI, No: GVOP-3.1.1.-2004-05-0544/3.0).

\section{APPENDIX}

\section{VLE parameters:}

a. Antoine parameters:

$\ln (\mathrm{p})=\mathrm{A}-\frac{\mathrm{B}}{\mathrm{T}+\mathrm{C}}$

where $\mathrm{p}$ vapour pressure [torr], $\mathrm{T}$ temperature $[\mathrm{K}]$

\begin{tabular}{|c|c|c|c|}
\hline component & A & B & C \\
\hline Water & 18.3040 & 3816.40 & -46.13 \\
\hline EDA & 16.408 & 3108.5 & -72.15 \\
\hline Ethanol & 18.912 & 3804.0 & -41.68 \\
\hline Toluene & 16.266 & 3242.4 & -47.181 \\
\hline
\end{tabular}

\section{b. UNIQUAC parameters}

Water $(\boldsymbol{A})-\operatorname{EDA}(\boldsymbol{B})$ :

\begin{tabular}{|cc|c|c|}
\hline $\mathrm{i}$ & $\mathrm{j}$ & $\mathrm{u}_{\mathrm{ij}}-\mathrm{u}_{\mathrm{ji}}[\mathrm{cal} / \mathrm{mol}]$ & $\mathrm{u}_{\mathrm{ji}}-\mathrm{u}_{\mathrm{ii}}[\mathrm{cal} / \mathrm{mol}]$ \\
\hline $\boldsymbol{A}$ & $\boldsymbol{B}$ & -19.6564 & -790.52 \\
\hline
\end{tabular}

Ethanol (A) - Toluene $(\boldsymbol{B})$ :

\begin{tabular}{|cc|c|c|}
\hline $\mathrm{i}$ & $\mathrm{j}$ & $\mathrm{u}_{\mathrm{ij}}-\mathrm{u}_{\mathrm{ji}}[\mathrm{cal} / \mathrm{mol}]$ & $\mathrm{u}_{\mathrm{ji}}-\mathrm{u}_{\mathrm{ii}}[\mathrm{cal} / \mathrm{mol}]$ \\
\hline $\boldsymbol{A}$ & $\boldsymbol{B}$ & -174.305 & 961.671 \\
\hline
\end{tabular}

